\title{
CHRONIC SUPPURATIVE OTITIS MEDIA PROFILE OF AEROBIC PATHOGENS
} AND ANTIBIOTIC SENSITIVITY

\author{
G. Jyothi Lakshmi1 ${ }^{1}$, Geeta², Swarajya Lakshmi ${ }^{3}$
}

\section{HOW TO CITE THIS ARTICLE:}

G. Jyothi Lakshmi, Geeta, Swarajya Lakshmi. "Chronic Suppurative Otitis Media Profile of Aerobic Pathogens and Antibiotic Sensitivity". Journal of Evolution of Medical and Dental Sciences 2014; Vol. 3, Issue 70, December 15; Page: 14957-14962, DOI: 10.14260/jemds/2014/4011

\begin{abstract}
CSOM is the inflammation of middle ear or mastoid cavity characterized by recurrent or persistent ear discharge through a perforation of tympanic membrane. Mortality and disabilities are primarily related to complications particularly brain abscess. Knowledge of local pattern of infection is essential to enable efficient treatment of the disease, thereby reducing the risk of complications. AIM: To study the prevalent organisms and their antibiotic sensitivity pattern among patients presenting with ear discharge in our hospital. SETTINGS AND DESIGN: Patients attending ENT OPD of a government hospital in South India, with complaints of ear discharge with or without pain were included in the study. MATERIALS AND METHODS: Total of 97 patients were studied. Ear discharge was collected on two sterile cotton swabs one used for microscopy (Grams and $\mathrm{KOH}$ ) and another for culture (Aerobic bacterial and fungal culture). RESULTS: Pseudomonas aeruginosa was the most common isolate (41\%) followed by Staphylococci (28.2\%). Gram negative bacteria showed good sensitivity to Cefotaxime (75.9\%) Gentamycin (74.5\%) and Amikacin (64\%). Gram positive cocci showed high degree of sensitivity to Gentamycin (98\%), Amikacin (89\%) and Cefotaxime (71.4\%). CONCLUSION: Study of local prevalence of bacteria and their sensitivity pattern helps in empirical therapy and reduces the risk of complications.
\end{abstract}

KEYWORDS: CSOM, Aerobic bacteria, Pseudomonas, Staphylococcus, Antibiotic sensitivity.

INTRODUCTION: Chronic suppurative otitis media (CSOM) is inflammation of the middle ear or mastoid cavity, characterized by recurrent or persistant ear discharge through a perforation of tympanic membrane. Bacteria can gain entry into middle ear via the external ear canal resulting in otorrhoea. CSOM and its complications are among the most common conditions seen by otologists and general practitioners. This potentially dangerous clinical condition is difficult to treat because the most common infecting organisms are often resistant to many antibiotics. In 1990's, 28000 deaths were due to CSOM primarily related to complications particularly brain abscess.(1)

CSOM has received considerable attention not only because of its high incidence and chronicity but also issues such as bacterial resistance and ototoxicity with both topical and systemic antibiotics.(2) The main stay of treatment for uncomplicated CSOM is twofold: meticulous aural toilet and instillation of a topical antimicrobial agent. Knowledge of the local micro-organisms pattern causing CSOM and their antibiotic sensitivity is therefore essential to start an effective and cost saving treatment.(3)

This study was done to determine the microbial diversity and the resistogram of aerobic bacterial isolates among the patients suffering from CSOM who attended ENT Department of our Hospital.

MATERIALS AND METHODS: This prospective study was carried out in Gandhi Medical College / Hospital Musheerabad, Secunderabad over a period of 6 months. Patients presenting to ENT OPD of 


\section{ORIGINAL ARTICLE}

our hospital with symptoms of ear discharge with or without pain were included in the study. Patients on antibiotics for the past 5 days were excluded. Demographic details of the patients were collected.

A total of 97 patients were included in the study. The ear discharge was collected on two swabs one used for microscopy and the second for culture. $\mathrm{KOH}$ mount and gram stain was performed. Culture was done on Mac Conkey Agar, Blood Agar, and Sabauraud's Dextrose Agar. Bacterial isolates were identified by standard biochemical tests( ${ }^{(4)}$ and antibiotic sensitivity test was done by Kirby Bauer disc diffusion method.(5) Mycelial fungal isolates were identified on LCB mount and yeast by gram stain morphology, germ tube and sugar assimilation and fermentation tests.

Institutional ethical committee approval was obtained for the study.

\section{RESULTS:}

\begin{tabular}{|c|c|c|}
\hline Age in Years & No. of Patients & Percentage \\
\hline$<10$ & 15 & $20.5 \%$ \\
\hline $11-20$ & 22 & $30 \%$ \\
\hline $21-30$ & 16 & $22 \%$ \\
\hline $31-40$ & 12 & $16.4 \%$ \\
\hline $41-50$ & 2 & $2.7 \%$ \\
\hline$>50$ & 6 & $8.2 \%$ \\
\hline Total & 73 & \\
\hline \multicolumn{2}{|c|}{ pable1: Distribution of culture positive } \\
patients based on age group
\end{tabular}

\begin{tabular}{|l|l|}
\hline No. of patients & 97 \\
\hline Samples with growth & 73 \\
\hline No bacterial growth & 24 \\
\hline Total isolates & 82 \\
\hline
\end{tabular}

\section{Table 2: Total Isolates}

\begin{tabular}{|l|c|c|c|c|c|}
\hline & Our Study & $\mathbf{2}$ & $\mathbf{3}$ & $\mathbf{8}$ & $\mathbf{9}$ \\
\hline Monobacterial growth & $74 \%$ & $74 \%$ & $64 \%$ & $39 \%$ & $70 \%$ \\
\hline Polymicrobial growth & $4 \%$ & $14 \%$ & $46 \%$ & $11 \%$ & $15 \%$ \\
\hline
\end{tabular}

Table 3: Distribution of Monobacterial and Polymicrobial Growth

Note: 2, 3, 8, 9 indicate reference numbers. 


\section{ORIGINAL ARTICLE}

\begin{tabular}{|c|c|c|c|}
\hline & Microorganisms & Number & Percentage \\
\hline \multirow[t]{5}{*}{ GNB } & Pseudomonas & 32 & $41 \%$ \\
\hline & Esch.coli & 04 & $5.1 \%$ \\
\hline & Klebsiella & 03 & $3.8 \%$ \\
\hline & Proteus vulgaris & 06 & $7.6 \%$ \\
\hline & Citrobacter & 02 & $2.5 \%$ \\
\hline \multirow[t]{3}{*}{ GPC } & CPS & 22 & $28.2 \%$ \\
\hline & CONS & 02 & $2.5 \%$ \\
\hline & S.pneumoniae & 03 & $3.8 \%$ \\
\hline \multirow[t]{3}{*}{ Fungi } & Candida & 01 & $1.3 \%$ \\
\hline & Aspergillus niger & 03 & $3.8 \%$ \\
\hline & Total & 78 & $100 \%$ \\
\hline
\end{tabular}

Table 4: Type of organisms isolated from CSOM patients

\begin{tabular}{|l|c|}
\hline \multicolumn{1}{|c|}{ Antibiotic } & Sensitivity Percentage \\
\hline Ampicillin & $15 \%$ \\
\hline Cotrimoxazole & $18 \%$ \\
\hline Amikacin & $68 \%$ \\
\hline Ofloxacin & $75 \%$ \\
\hline Cefotaxime & $71.8 \%$ \\
\hline Ceftazidime & $75 \%$ \\
\hline Gentamycin & $69 \%$ \\
\hline \multicolumn{2}{|c|}{ Table 5: Antibiotic sensitivity } \\
of Pseudomonas (n=32)
\end{tabular}

\begin{tabular}{|l|c|}
\hline \multicolumn{1}{|c|}{ Antibiotic } & Sensitivity Percentage \\
\hline Ampicillin & $20 \%$ \\
\hline Cotrimoxazole & $13.3 \%$ \\
\hline Amikacin & $60 \%$ \\
\hline Cefotaxime & $80 \%$ \\
\hline Ceftazidime & $60 \%$ \\
\hline Gentamycin & $80 \%$ \\
\hline
\end{tabular}

Table 6: Antibiotic sensitivity of coliforms $[(\mathrm{n}=15)$

E.coli-4, Kleb-3, Proteus-6, Citrobacter-2] 


\section{ORIGINAL ARTICLE}

\begin{tabular}{|l|c|}
\hline \multicolumn{1}{|c|}{ Antibiotic } & Sensitivity Percentage \\
\hline Amikacin & $89 \%$ \\
\hline Ofloxacin & $65 \%$ \\
\hline Netilmicin & $70 \%$ \\
\hline Erythromycin & $54 \%$ \\
\hline Rifampicin & $50 \%$ \\
\hline Vancomycin & $28 \%$ \\
\hline Oxacillin & $16.6 \%$ \\
\hline Cefotaxime & $71.4 \%$ \\
\hline Ampicillin & $62.5 \%$ \\
\hline Cotrimoxazole & $12.5 \%$ \\
\hline Gentamycin & $98 \%$ \\
\hline \multicolumn{2}{|c|}{ Table 7: Antibiotic sensitivity of gram } \\
\hline
\end{tabular}

DISCUSSION: CSOM is defined as chronic inflammation of the middle ear and mastoid cavity which presents with recurrent ear discharges or otorrhoea through a tympanic membrane perforation. It is classified into 2 types tubotympanic and attico antral depending on whether the disease process affects the pars tensa or pars flaccida of tympanic membrane. Tubotympanic is called as a safe type or benign type as there is no serious complication whereas attico-antral is called as the unsafe or dangerous type because of associated complications. Infection can spread from middle ear to vital structures such as mastoid, facial nerve, labyrinth, lateral sinus, meninges and brain leading to mastoid abscess, facial nerve paralysis, deafness, lateral sinus thrombosis, meningitis and intra cranial abscess. Of all the complications, hearing loss associated with chronic ear discharge is nearly always significant reported in $50 \%$ of cases and tending to be more severe than those reported in other types of otitis media.(6)

Early microbial diagnosis in all cases is important for prescribing appropriate treatment.

Of 97 patients included in the study, maximum patients were in the age group of 11-20 years (30\%), 50\% of cases were in the age group of less than 20 years. High prevalence of CSOM in children and young adults is because, the eustachian tube is short and wider and so are more prone to upper respiratory tract infection. (Table-1).

Male to female ratio was found to be 1:1. Of 97 patients samples processed, 73 yielded growth and 24 showed no growth. Fungi were isolated in 4\%. (Table-2)

\begin{tabular}{|c|l|c|c|c|c|c|c|c|c|}
\hline S. No & \multicolumn{1}{|c|}{ Isolates } & Present Study & $\mathbf{1}$ & $\mathbf{3}$ & $\mathbf{7}$ & $\mathbf{8}$ & $\mathbf{9}$ & $\mathbf{1 0}$ & $\mathbf{1 1}$ \\
\hline 1. & Pseudomonas & $\mathbf{4 1 \%}$ & $19.5 \%$ & $18 \%$ & $41 \%$ & $54 \%$ & $34 \%$ & $27 \%$ & $45 \%$ \\
\hline 2. & E.Coli & $\mathbf{5 . 1 \%}$ & $2.4 \%$ & $3.1 \%$ & $9.5 \%$ & $3.2 \%$ & $2.6 \%$ & $7 \%$ & $4.7 \%$ \\
\hline 3. & Klebsiella & $\mathbf{3 . 8 \%}$ & ND & $6.2 \%$ & $10 \%$ & $8 \%$ & $13 \%$ & $10.4 \%$ & $6.3 \%$ \\
\hline 4. & P. vulgaris & $\mathbf{7 . 6 \%}$ & $3.7 \%$ & $25 \%$ & $5.5 \%$ & $6 \%$ & $6.5 \%$ & $7 \%$ & $4.7 \%$ \\
\hline 5. & Citrobacter & $\mathbf{2 . 5 \%}$ & $1.8 \%$ & ND & ND & ND & ND & ND & ND \\
\hline 6. & CPS & $\mathbf{2 8 . 2 \%}$ & $56 \%$ & $28.6 \%$ & $30 \%$ & $11.3 \%$ & $27 \%$ & $28.6 \%$ & $22 \%$ \\
\hline 7. & CONS & $\mathbf{2 . 5 \%}$ & $5.5 \%$ & $15.6 \%$ & ND & $8 \%$ & $15.8 \%$ & $15.6 \%$ & $7.9 \%$ \\
\hline
\end{tabular}




\section{ORIGINAL ARTICLE}

\begin{tabular}{|c|l|c|c|c|c|c|c|c|c|}
\hline 8. & S.pneumoniae & $\mathbf{3 . 8} \%$ & ND & $1.5 \%$ & ND & $1.6 \%$ & ND & $1.5 \%$ & ND \\
\hline 9. & Aspergillusniger & $\mathbf{3 . 8} \%$ & ND & ND & ND & ND & ND & $6.9 \%$ & ND \\
\hline 10. & Candida & $\mathbf{1 . 3} \%$ & ND & ND & ND & ND & ND & $2.6 \%$ & ND \\
\hline
\end{tabular}

Table 8: Comparision of isolation rates of pathogenic organisms in patients of CSOM from various studies

Note: 1, 3, 7, 8, 9, 10, 11 indicate reference numbers ND-No Data.

$74 \%$ samples yielded monobacterial isolate in our study. This was in agreement with the studies of Shazia et al and Raakhee et al. Shresta et al reported much lower rates of single bacterial isolate $39 \%$. In our study polybacterial isolates were observed in $4 \%$ of samples tested. However other studies showed a range between $11 \%$ to $46 \%$. (Table-3)

Among the fungi aspergillus species was isolated in 3.8\% of cases Shresta et al reported 6.9\% isolates of the same.

The most common bacterial isolate was Pseudomonas $n=32 \%$ (41\%) which correlated with study of Arvind N et al, Prayaga N Srinivas Moorty et al and Shazia Parveen. Pseudomonas is the most prevalent organism in tropical region like ours. It does not usually inhabit upper respiratory tract. Its presence in middle ear cannot be ascribed to an invasion through Eustachian tube but should be considered as secondary invader gaining access to middle ear via defect in Tympanic Membrane (Rajat Prakash). (Table-8)

Staphylococcus aureus was the next common isolate in our study. This pattern was in tandem with the study of Sateesh Kumar. However S. aureus as the predominant isolate was reported by AH Singh et al, Shamweel Ahmed et al, Arvind et al and Shresta et al. This difference in results of various authors could have been due to the difference in the patient population studied and geographical variations. (Table-8)

$24 \%$ of samples did not yield growth of bacteria or fungi.

Gram negative bacteria were the predominant isolate $60.4 \%$ followed by gram positive cocci $34.5 \%$ and $5.1 \%$ of isolates were fungi including yeast. GNB isolated in this study showed a high sensitivity to cefotaxime (75.9\%) and gentamycin (74.5\%) followed by Amikacin (64\%).

(Table-4, 5, 6)

Staphylococci showed a high degree of sensitivity to Gentamycin (98\%) Amikacin (89\%) followed by Cefotaxime (71.4\%). (Table-7)

CONCLUSION: Continuous and periodic evaluation of microbiological pattern and antibiotic sensitivity of isolates is necessary to initiate effective treatment protocols for the study population. It also decreases the potential risk of complications by early institution of appropriate treatment. Untreated cases of CSOM can result in a broad range of complications like persistent otorrhoea, mastoiditis, labyrinthitis, meningitis and facial nerve palsy. Some patients may develop life threatening complications like lateral sinus thrombosis or brain abscess also. Hence treatment has to be initiated early and effectively.

As higher incidence of CSOM was seen among children, educating parents and guardians on possible risk factors of the disease may be a preventive strategy that might reduce disease occurrences. 


\section{ORIGINAL ARTICLE}

\section{REFERENCES:}

1. Shamweel Ahmed, Antibiotics in chronic suppurative otitis media: A bacteriologic study, Egyptian Journal of Ear, Nose, Throat and Allied Sciences (2013) 14, 191-194.

2. Shazia Parveen. S and Janardhan Rao R., Aerobic bacteriology of Chronic Suppurative Otitis Media (CSOM) in a teaching hospital, J. Microbiol. Biotech. Res., 2012, 2(4):586-589.

3. AH Singh, R Basu, A Venkatesh, Aerobic bacteriology of chronic suppurative otitis media in Rajahmundry, Andhra Pradesh, India, www.biolmedonline.com, Biology and Medicine, 4(2):7379, 2012.

4. Mackie and Mccartney Practical Medical Microbiology, 14th Edition.

5. Performance standard for antimicrobial disk susceptibility tests, approved standard, January 2012, MO2-Aii, Vol. 32, No-1.

6. Rajat Prakash, Deepak Juyal, Vikrant Negi, Shekhar Pal, Shamanth Adekhandi, Munesh Sharma, Microbiology of Chronic Suppurative Otitis Media in a Tertiary Care Setup of Uttarkhand State, India, N Am J Med Sci, Apr 2013; 5 (4): 282-287.

7. Arvind N, Pavan Chand and Vishrutha KV, Microbiological profile of Chronic Suppurative Otitis Media, International Journal of Biomedical Research, (2014) 05 (03).

8. Prayaga N. Srinivas Moorthy, Jadi Lingaiah, Sudhakar Katari, Anil Nakirakanti, Clinical Application of a Microbiological Study on Chronic Suppurative Otitis Media, IJOHNS, 2013, 2, 290-294.

9. Raakhee T, Sreenivasa Rao Unguturu, Bacteriological study of discharging ear in patients attending a tertiary care hospital, International Journal of Research in Medical Sciences AprilJune 2014, Vol 2, Issue 2, Page 602.

10. Shrestha BL, Amatya RCM, Shrestha I, Ghosh I, Microbiological Profile of Chronic Suppurative Otitis Media, Nepalese Journal of ENT Head \& Neck Surgery, Vol. 2 No.2, Issue 2 (July-Dec 2011).

11. Sateesh Kumar Malkappa, Saileela Kondapaneni, Rajendra Bhaudas Surpam, Trinain Kumar Chakraverti, Study of aerobic bacterial isolates and their antibiotic susceptibility pattern in chronic suppurative otitis media, Indian Journal of Otology, July 2012, Vol. 18, Issue 3.

\section{AUTHORS:}

1. G. Jyothi Lakshmi

2. Geeta

3. Swarajya Lakshmi

\section{PARTICULARS OF CONTRIBUTORS:}

1. Associate Professor, Department of Microbiology, Gandhi Medical College, Hyderabad.

2. Post Graduate, Department of Microbiology, Gandhi Medical College, Hyderabad.

3. Associate Professor, Department of Microbiology, MNR Medical College, Sangareddy.
NAME ADDRESS EMAIL ID OF THE CORRESPONDING AUTHOR:

Dr. Jyothi Lakshmi, Associate Professor, Department of Microbiology, Gandhi Medical College, Hyderabad.

Email: drgjyothilakshmi@yahoo.com

Date of Submission: 27/11/2014.

Date of Peer Review: 28/11/2014.

Date of Acceptance: 10/12/2014.

Date of Publishing: 13/12/2014. 